\title{
Working Through Disagreement in Deliberative Forums
}

\author{
Brian Adams \\ Professor \\ Political Science Department \\ San Diego State University \\ badams@mail.sdsu.edu
}

\begin{abstract}
Working through disagreement is a core deliberative activity, yet there is little theorizing over how disagreement actually unfolds during deliberation. In this paper I develop a framework identifying five aspects of working through disagreement that can vary within deliberative contexts. I use this framework to explore how people address disagreements during eight National Issues Forums. When participants disagreed on an issue there was often little back-and-forth exploring differences, with issues being dropped quickly in favor of other topics. In the rare cases when disagreements were explored in some detail, the conversations often lacked clarity and coherence. There is little evidence that working through disagreement is a common activity during forums. I conclude the paper by exploring how the way in which disagreements are addressed can impact the likelihood of realizing desired goals such as reaching common ground, mutual understanding, and political learning.
\end{abstract}

Presented at the 2013 annual meeting of the Western Political Science Association, March $28^{\text {th }}-30^{\text {th }}$, Hollywood, CA. 


\section{Working Through Disagreement in Deliberative Forums}

Disagreements are inevitable in deliberation, and thus a key part of deliberation is for participants to work through them. Many deliberative democrats view this process of working through competing claims as a core task of deliberative talk (Barber 1984; Bickford 1996; Mathews 1999; Cohen 1998; Price, Cappella, and Nir 2002; Delli Carpini, Cook and Jacobs 2004; Stromer-Galley 2007; Fishkin 2009). Deliberators need to do more than simply state opposing viewpoints and then vote on them (as aggregative models of democracy allow for). If a deliberator states an argument, those who disagree with it should explain why they disagree, with the ensuing discussion exploring the contours of conflict, the logic of arguments made, and the underlying premises giving rise to differing opinions.

There are many ways that deliberators could approach disagreements once they arise during discussion. Some may actively avoid addressing disagreement, preferring to change the topic or feign consensus. Others may directly challenge others with probing questions and contradictory evidence. Still others may show disagreement in an indirect way by presenting alternate viewpoints without any direct confrontation. The goal is this paper is to develop a systematic framework that can be used to empirically explore variations in how deliberators address and manage disagreement. Such a framework is necessary to examine deliberative theorists' claims about the benefits of deliberation for society. How deliberators address disagreement has a critical impact on the likelihood of achieving desired goals, such as reaching common ground, mutual understanding, and political learning. In order to tease out the causal connections between these goals and deliberation, we need to break down the concept of "working through disagreement" into its component parts and explore the variations in how this is done. The empirical analysis in this paper, which applies the framework to eight National Issues Forums, is exploratory, highlighting the value of the framework and the issues that future research needs to explore.

\section{Working Through Disagreement: A Framework}

Gutmann and Thompson (1996) place disagreement at the center of deliberative practice: when there are moral disagreements over the appropriate course of action, citizens should deliberate over the issue, offering reasons that appeal to the public good and meet certain principles of fairness. After arguing that a deliberative approach is superior to both procedural and constitutionalist approaches, they develop a theory regarding the appropriate content of arguments during deliberation, contending that deliberators should offer mutually-acceptable reasons that are grounded in the public good. Thus, their work explains why we should have an exchange of reasons over moral disagreements and the preferred content of those reasons. What they neglect to do is take the next step and explore how citizens should exchange reasons, putting the process of deliberation itself into a "black 
box." So person A makes a moral argument that comports with Gutmann and Thompson's criteria but person B disagrees and offers a different argument. What happens then? Presumably there would be an exchange of ideas, some type of back-and-forth to "work through" the issue, but this process is not theorized. Gutmann and Thompson seem to assume that if deliberators make mutually acceptable arguments, a robust deliberative process will follow. But there are many ways that people can go about discussing moral disagreements, and there is no guarantee that good arguments lead to a good discussion. What is missing is a theory of how deliberators exchange ideas to work through disagreements.

The literature attaches great importance to this process of working through disagreement, stressing that deliberators need to "weigh" choices in a "free" and "open" exchange (Barber 1984; Bohman 1996; Mathews 1999; Cohen 1998; Fishkin 2009). For example, Gastil $(2008,20)$ identifies "weigh[ing] the pros, cons, and trade-offs among solutions" as a core activity of deliberation. Yet, there is little discussion as to what "working through" actually constitutes and how it contributes to desired deliberative outcomes. In particular, the "weighing" metaphor is often thrown around without any development, as if it was not a metaphor but rather a literal description of how deliberators acted (presumably involving putting ideas on scales). Disagreement can take different forms and the process of working through disagreement can exhibit many variations. Below I explore five aspects of working through disagreement that can vary across groups:

1.) The disposition of deliberators towards disagreement

2.) The type of disagreement

3.) The directness of the critique

4.) The quality of the exchange

5.) The resolution of the exchange

Deliberators may have a predisposition against acknowledging and working through disagreement. Hibbing and Theiss-Morse (2002) have argued that the majority of Americans are turned off by political conflict and subscribe to a model of politics that assumes there is a "right" way to solve social problems. If one views the pursuit of the "common good" as the goal of politics, and believes that there is an objective and obvious common good, this will create a disposition against airing conflict and working through disagreement (see Eliasoph (1998) for an alternative explanation for Americans' avoidance of political conflict). Participants could also avoid disagreement because they see deliberation as being more educative rather than confrontational (Button and Mattson 1999). If one sees deliberation as an exercise in civic learning, it may not be necessary to work through differences; stating ideas will be sufficient. But these attitudes can vary depending on the nature of the issue and composition of the deliberative group. Deliberators may see 
conflicts over some issues as more amenable to deliberation than others. For example, they may be willing to engage disagreement over energy policy but avoid it when it comes to abortion, under the premise that "morality" issues such as abortion do not lend themselves to reasoned discussion. The same goes for assessment of one's fellow deliberators: participants may be willing to engage disagreement if they believe others are open-minded enough to listen and reflect on opposing viewpoints. Thus, there is a wide range of dispositions that deliberators could bring to the table depending on their understanding of politics generally, their understanding of the purpose of deliberation, the nature of the issue under discussion, and the assessment of potential for others to alter their views.

A second aspect of disagreement that varies is the form the disagreement takes. Disputes could be of a factual nature (disagreement over an existing condition) or they can be over policy proposals (what should be done). The source of the latter type could be a result of a fundamental disagreement over values, either in terms of whether something is valuable or the relative weight that we should assign to values. If deliberators agree on values they could still dispute the specifics of proposals, such as whether a tradeoff is worth making or the consequences of taking certain actions. The causal logic of proposals could be in dispute, where deliberators disagree about the appropriateness of a proposal to a problem or the potential for unintended consequences. Gutmann and Thompson (1996) focus on moral disagreements, but not all disputes within deliberation are of this sort; deliberators may agree on moral issues but still have fundamental disagreements that prevent reaching a consensus on policy issues.

The third aspect of disagreement is the directness of the critique offered by deliberators. When person A makes a statement with which person B disagrees, she has some options as to how to respond (assuming that she desires to make a response). She could offer a direct critique of person A's proposal, exposing a logical flaw or questioning a premise. Alternatively, she could present a counter proposal that indicates a different way of addressing the issue at hand. This is an indirect way of expressing disagreement: rather than explicitly stating the reasons for why person A's proposal is flawed, person B is making an argument for a different proposal that she finds better. There is an implied critique of person A's proposal but it is not explicitly stated. Even if person B offers a critique of person A's proposal, it may be presented in an indirect way by couching it in a question or using linguistic expressions such as "yeah, but...". There are many conversational conventions that could make a critique either more or less direct. Thus, this is a continuous variable between an explicit critique of a statement to an implicit critique offered through an alternate proposal.

A fourth way that disagreement varies is in the quality of the exchange. "Quality" here refers to the ability of deliberators to clarify the nature of the disagreement and 
articulate the ways in which they disagree. A low quality exchange could be the result of either an unwillingness or inability to engage others. As discussed above, some deliberators may be predisposed to avoid conflict or paper over disagreements, which could result in a short, low quality exchange (assuming there is an exchange at all). For example, deliberators could acknowledged differences but then simply "agree to disagree" and move on to other topics. We might also see low quality exchanges when deliberators identify a point of disagreement but are unable to articulate why they disagree. For example, a deliberator could express opposition to a particular policy proposal but not explain what they find wrong with, or they could attempt an explanation but not articulate it clearly.

A final way that deliberation can vary in relation to disagreement is how the disagreement is resolved. The possible outcomes here are straightforward. Consensus is a possible but unlikely outcome, as it requires that some deliberators change their opinions. Compromise is also possible, but in many deliberative contexts there are few incentives for participants to engage in negotiations that would lead to such an outcome. Deliberators may also identify "common ground" where they agree on some specific proposals despite remaining divided on larger questions (See Sanders (1997) for a critique). Another possibility is that there is no resolution; disagreements are identified and then dropped, either because deliberators are unable to reach some type of resolution, because they prefer to avoid the conflict required to forge an agreement, or because conversational dynamics led them to a different topic before a resolution emerges.

These five factors highlight the variation that can occur when disagreements are present during deliberation. This framework is useful in identifying the ways in which disagreements vary and classifying and documenting disagreements with deliberative forums. The rest of this paper applies this framework to a set of eight National Issues Forums in an effort to both demonstrate the value of the framework as well as suggest that many of the assumptions that deliberative theorists make about disagreement are questionable, and that the manner in which citizens deal with disagreement may limit the theorized benefits of deliberation.

Data and Methods

This study analyzes eight National Issues Forums (NIF) conducted between 2004 and 2007, listed on table 1. NIF is a network of civic organizations that promotes deliberative discourse by hosting forums on a policy problem, loosely structured around issues books produced by the Kettering Foundation. Each forum had between 14 and 24 participants and lasted approximately $1 \frac{1 / 2}{2}$ to 2 hours. During the forum, the moderator leads the discussion through the three or four options listed in the issue book, but the conversation is not rigidly structured: deliberators are free to bring up any relevant points and are 
encouraged to engage in back-and-forth exchanges with others (participants typically sit in a circle to facilitate this).

Deliberators were self-selected, although forum organizers made efforts to promote diversity. Systematic demographic data were not available, but during many of the forums deliberators introduced themselves (providing their occupation) and other demographic information was often revealed throughout the forum. There was minimal gender bias (participants were 54\% male) but there appeared to be a strong SES bias, consistent with other research on self-selected forums (Goidel et al 2008). Most notable was an education bias; because many of the forums were held at university campuses, there is an overrepresentation of university staff, faculty and students. There was, however, a good age mix, with participants ranging from teenagers to retirees. Some forum organizers invited elected officials (two members of congress and a few local officials) to the forums, but they were not given any "special treatment" or deference either by the moderator or the other deliberators, and in none of the forums did they dominate the discussion or act in a capacity other than as a deliberator (i.e. they did not give speeches or assume the role of an "expert"). In general, each forum had a diverse mix of participants, notwithstanding the SES bias.

Transcripts of each forum were coded to identify instances of disagreement, which is the unit of analysis for this study. For a disagreement to occur, at least two deliberators needed to take mutually exclusive positions on an issue relevant to the topic of the forum. The distinguishing characteristic of disagreement is that the positions are mutually exclusive; slightly different ways to define a problem or differences in emphasis were not coded as disagreements. Quarrels with the contents of the NIF issue book, or with the moderator's presentation of the issue, were also not coded as disagreements. The two mutually exclusive statements must have occurred within three comments of each other (this is a practical criterion necessary for coding, as it is impossible for coders to keep in mind all of the previous comments and determine whether a given comment is in opposition to any previous comment). The beginning of a disagreement exchange is the first mutually exclusive statement, and the endpoint was identified as when there was a topic change away from the specific point of disagreement. Applying these coding rules resulted in the identification of 37 disagreements during the eight forums, which are listed on table 2.

Below I examine these 37 instances of disagreement to explore the five characteristics of disagreement described above. The methods are largely qualitative, exploring the nuances and complexities of how deliberators approach disagreement. All names used are pseudonyms.

Analysis 
Participants' disposition towards disagreement can be measured in a few different ways. One is to administer a survey questionnaire that probes their attitudes towards deliberation, such as whether they see it as a means to work through conflict or more of a learning process. They could also be queried regarding their willingness to engage in conversations with others who disagree with their views and their attitude towards disagreement in politics more generally. The shortcoming of surveys is that social desirability bias may color respondents' answers: it is unlikely that many respondents would indicate an intolerance towards, and unwillingness to engage, opposing viewpoints. Another way to measure participants' approach to disagreement is to infer attitudes from their behavior during forums. The amount of disagreement during forums could indicate participants' (un)willingness to engage others, although this is influenced not just by their dispositions towards disagreement but also the extent to which they actually hold differing views. A better way to assess willingness to engage disagreement is the length and robustness of exchanges when disagreements are identified. Quickly moving on from an identified points of disagreement indicates an unwillingness to work through conflicts, while lengthy exchanges where arguments are made in defense of opposing positions shows a willingness to engage others.

One notable characteristics of table 2 is how few disagreements there were -37 total, making for an average of less than five per forum. Further, once we take out disagreements over factual questions, there were only 22 disagreements over policy proposals (less than three per forum). One possibility for the lack of disagreement could be that the participants were skewed towards one position or another and thus largely agreed on the issues under discussion. This, however, was not the case: even though the participants were self-selected, there was a wide range of ideological positions represented. This is reflected in the types of issues on which they did express disagreement, such as foundational principles on the role of government in society and the morality of limiting immigration. It was clear from the discussion that deliberators had different worldviews and approached the issue under discussion in divergent ways. Thus, the limited number of disagreements is caused by something other than an existing consensus on the issue.

When disagreements did surface, the exchanges between deliberators were often quite short. The shortest exchanges consisted just of the initial statement and a critique, with no rebuttal or further exchange. The longest exchange had 20 comments (a debate over universal healthcare in Pittsburgh). The average exchange had around seven comments, although in some cases comments included within an exchange were extraneous or tangential to the disagreement itself. There is no magic number as to the desired length of exchanges for working through disagreement. In principle, a statement and critique 
combination may be sufficient, if the critique is persuasive or highlights the core of the disagreement. In practice, such a simple exchange is usually not sufficient to work through complex policy proposals. Most statements and critiques do not fully articulate reasons for disagreement; there needs to be further elaboration in order to develop the arguments for and against a proposal. Typically a few back-and-forths are necessary to explore the nature of the disagreement, and the more fundamental the disagreement the more exchanges are necessary to explore it. For many of the disagreements listed on table 2, this was conspicuously absent.

Some of the disagreements did exhibit extensive working through. For example, in Georgetown four deliberators engaged in a debate over whether immigrants should be required or forced to learn English (involving about 15 comments). Two of the deliberators identified problems caused by immigrants not being able to speak English, which prompted response from others ether along the lines of "immigrants will learn English eventually so it's not a problem" or that it would be better if native English speakers learned Spanish. This exchange highlighted some core aspects of the debate, and even though it was not resolved (the moderator cut it off to move to a different topic), it did exhibit some measure of "working through." But this type of exchange was an exception: most disagreements involved only a few comments with little back-and-forth. For a few of the factual disagreements, there were only two comments: the initial one and the critique, with no follow up. With others, there were two or three responses to the original comments but no rebuttal from the deliberator making the initial comment. For example, during the Cedar Rapids forum, Laura argued that the United States should increase the number of immigrants it allows into the county, prompting a response from Sarah that too much population growth will lead to major problems. However, Laura never had a chance to respond because another point Sarah made during her comment regarding the taxes that immigrants pay pushed the conversation in a different direction. Another example occurred in the Rindge forum where a few deliberators indicated that we should not focus solely on economics when thinking about immigration levels (this is a critique of one of the choices listed in the issue book). Mary responds by defending an economic focus because it encompasses "other dimensions," but her thoughts were not responded to as the moderator interjected and moved to a different topic.

In general there were few disagreements that were explored with an extensive backand-forth of ideas. We do not have the necessary information to explain the specific reasons behind this pattern; it is unclear whether it is a result of an intentional effort to avoid conflict or a result of conversational dynamics that unintentionally stifled the engaging of opposing viewpoints. Thus, we cannot make a definitive conclusion regarding the disposition of participants towards disagreement. That said, the relative dearth of 
disagreements and the brevity of exchanges when disagreements did arise suggests that deliberators were not completely comfortable with working through disagreement.

\section{The Type of Disagreement}

15 of the 37 disagreements were of a factual nature, some of them on very specific points that came up in discussion. For example, in Kent a deliberator commented that plasma televisions use a lot of energy, only to be rebutted by someone claiming that they use less energy than CRT televisions. Another illustration comes from Rindge, where there was a debate over whether immigrants on H1B visas are paid less than other workers. Some of the other factual disagreements were more nebulous, with the nature of the disagreement being less clear-cut, such a dispute in Cedar Rapids over whether opposition to immigrants was primarily driven by racial prejudice, and a disagreement in Rindge concerning whether the United States needs to recruit nurses from overseas to meet demand. As for the disagreements over policy ( 22 total), they varied in terms of the fundamental source of the dispute. Some entailed a conflict over core values or principles, such as the exchanges in Mesa over amnesty for illegal immigrants and whether they should receive in-state tuition. Even though these debates involved other issues, at their core was a dispute over what constitutes a "fair" and "just" policy towards illegal immigrants. Similarly, some of the differences expressed in the energy and health care forums involved a fundamental disagreement over the role of government in society. Yet, other conflicts were less about values and more focused on competing causal assumptions. There were disagreements over the effects on immigration on the economy (and in particular on wages), the impact of incentive programs on individual behavior, and the effects of market incentives in the health care system. These debates revolved around alternate conceptions of what would happen if a given policy proposal were adopted. In general, there was no clear pattern as to the types of disagreements that arose during these forums, with disagreements ranging from narrow disputes over factual minutia to wide-ranging conflicts over core political principles and values.

\section{The Directness of the Critique}

A direct critique is when a deliberator disagrees with a statement by making a claim as to its falsehood or identifying a flaw in logic or premises (i.e. they need to identify something wrong with another deliberator's comment). An indirect critique is when a deliberator disagrees by offering an alternative proposal or making some other mutually exclusive statement without directly critiquing others. Thus, the central criterion here is whether deliberator B makes an explicit critique of A's comment or whether the critique is implied by making a contradictory statement. Factual disagreements were mostly direct critiques; even though it is possible to make an indirect critique of a factual statement by 
presenting contradictory facts without tying them to the first statement, in practice this was not common (only two of the 15 factual disputes were indirect). Thus, our focus here will be on policy disagreements.

Eight of the policy disagreement were indirect and 14 were direct. Even for the direct ones, deliberators found ways to "soften" their critiques. For example, in El Paso Robert suggests that we need some type of "global governance" to address energy issues, to which Elizabeth responds "The only thing that worries me about Robert's opinion is that in my personal views, I think that the United Nations has been a terrible failure," and proceeds to explain why. The "only thing that worries me" and "in my personal views" phrases have the effect of making a direct critique without making it seem confrontational. In Mesa, a deliberator responded to a proposal allowing illegal immigrants to pay in-state tuition by saying "Well I have the [laughter], well once again I probably have the unpopular opinion," and then proceeded to critique the proposal (he had raised objections to other proposals earlier in the forum). By highlighting his contrarian role he softened the force of the challenge. There were some instances, however, where deliberators came out with a direct, unmitigated "Well, I disagree" statement, although they were a distinct minority of casesusually direct critiques were soft-pedaled in some fashion.

The indirect critiques offered an alternative position on an issue without making an explicit critique of the initial statement. A good example comes from El Paso, where Don argues that we need a national approach to the energy problem (this happened much later, and is separate from, the "global governance" debate described previously). Jose responded by stating that the federal role should be limited to "providing information," which suggests an approach that is not primarily national, although he does not directly critique Don's proposal. Scott chimes in by stating that "Not everything has to be a government solution and most cases is not," explaining that private industry has market incentives to address energy issues. This is clearly a critique of Don's suggestion of a "national approach," but Scott does not directly explain why he finds it unattractive. Rindge provides another illustration of an indirect critique. A few deliberators offered arguments for why economic concerns should not drive American immigration policy (this was in response to one of the approaches in the issue book). Mary responds to their comments with "There's another aspect to this. I'm probably thinking about it a different way than other people maybe, but in a way I think, it's okay to talk about it on the level of economics right now." She then proceeds to explain how an economic perspective is valuable because economics is connected to issues of quality of life and community, but she does not directly critique the comments made by the previous speakers.

In general, for both direct and indirect critiques, deliberators soft-pedaled their statements. This can be valuable for maintaining cordiality during forums and prevent 
disagreements from becoming "personal." However, there is also a downside, as softpedaling can obscure the nature of the disagreement and make it difficult for participants to see the contours of the debate. This is particularly true of indirect critiques, which may stifle debates by neglecting to highlight core points of disagreement.

\section{The quality of the exchange}

Working through disagreement requires that the nature of the disagreement be clearly defined and articulated; without this, participants may "talk past one another" and fail to directly address each other's arguments. There are two parts to a quality exchange: that the disagreement is clearly defined and that the reasons behind the disagreement emerge. For factual disagreements, both of these conditions usually held, as the fact in dispute is identified and the reason behind the disagreement (varying factual information) is self-evident. One or two of the policy disagreements also exhibited such clarity. A Mesa debate over the effectiveness of day-laborer programs and a Kent proposal over the feasibility of wind power were both clearly defined disagreements and the underlying disputed points (the effectiveness of day laborer camps to match up employers with workers and the economic feasibility of wind power) were brought to the fore.

Notwithstanding these examples, in most instances the exchange did not serve to clarify the debate. An illustration comes from Mesa where a deliberator, Keith, argues that immigrants should have in-state tuition at community colleges, followed by a supportive comment from Carl. Manuel offers a dissenting view, arguing that education is a good investment and thus is not too high, prompting a response from Carl suggesting that documented immigrants should qualify for student loans as a compromise position. Manuel responds that if they are here legally they can start residency, implying they can receive instate tuition. This led Carl to say "We gotta fix the gap before we can tackle that," followed by the moderator changing topics. During this exchange the contours of the disagreement were never clearly outlined. It was unclear whether Keith was referring to legal or illegal immigrants (although given the context of a previous comment it seems he was referring to the latter). Carl's first comment specifically refers to illegal immigrants but his second comment seems to refer to legal residents, confusing the debate. This disagreement never got off the ground because it was unclear exactly what people were arguing about and as a result participants did not fully develop their arguments. There were other instances throughout the forums where the nature of the debate was never clearly defined, such as the "global governance" debate described above, where Robert never established what he meant by the term.

An example from Kent illustrates how the fundamental disputes underlying disagreements do not always surface. The debate centered on the role of government in 
promoting clean energy. Debra starts the conversation by stating that government should invest in developing alternative energy sources, prompting a reply from Aaron that we should rely on businesses, not government, for innovation and that the government is "too much involved in a lot of things." Randy then asks "Okay. The government could offer things like tax credits, right?" to which Aaron agrees but restates his preference for business over government. The conversation ends with a critique of how the department of energy operates and a brief discussion regarding the availability of ethanol. Even though there is clearly a disagreement and relevant issues were raised, the fundamental point of contention about the benefits and costs of government involvement was never articulated. This was a pattern that repeated itself throughout the forums: a disagreement arose but the exchange never got to the "bottom" of the dispute by identifying the core points of disagreement.

\section{Resolution}

It was quite rare for a disagreement to be "resolved" either with an emerging consensus, a compromise position, or someone conceding a point. There was one exchange - on wind power during the Kent forum — where a deliberator did concede a point after a rebuttal to his statement, but that was the only instance where there was any type of resolution. In some cases a critique (or alternative proposal) is simply ignored, with deliberators moving on to a different topic. This was not necessarily intentional: sometimes deliberators simply had other things they wanted to say and preferred to move on rather than go into the disagreement. Moderators were frequently responsible for ending exchanges. In some cases, moderators wanted to move on to the next approach (of which there were typically three) or needed to wrap up the discussion because they were running out of time. In other cases moderators appeared to want to organize the discussion but instead prompted deliberators to change topics. Resolution was also elusive at times because the conversation naturally moved onto another topic through deliberators exploring a tangent or related issue.

The fact that almost all of the disagreements ended before a resolution was achieved (or even approached) indicates an organizational problem with these types of forums. Because the topics are so broad there are many issues to cover, leading to less time for addressing each of them. There are no structural features than encourage participants to work through disagreements to some kind of terminus (even if that endpoint is "agreeing to disagree"). True, there are no structural features discouraging it, but as Ryfe (2005) notes, delving into the substance of complex policy issues is not something that is part of everyday reasoning habits. Putting people together in a room and giving them an issue book is not a sufficient prompt for deliberators to work through disagreements to a resolution. As a result, many disagreements are stillborn, never being explored or debated as we would hope to see in deliberative forums. 


\section{Disagreement and the Value of Deliberative Forums}

Deliberation proponents argue that it has numerous beneficial outcomes, such as reaching "common ground," increased understanding of opposing viewpoints, and political learning. The manner in which deliberators worked through disagreement, however, limited the potential for these benefits to materialize.

Deliberative democrats vary in their approach to agreement. For some, the ultimate goal of deliberation is consensus, although this is a decidedly minority view as most acknowledge that consensus is unlikely on controversial political issues (Mansbridge 1980). Barring consensus, some see compromise as the goal especially in deliberations organized to make an explicit recommendation to government (such as citizen juries). More commonly, deliberation proponents see "common ground" as the ultimate terminus. Here, deliberators still disagree on the fundamentals of the issue, but through discussing the issue they recognize areas where certain actions can be taken (Mathews 1999; Karpowitz and Mansbridge 2005). For example, deliberators may disagree over the best way to deal with the health care crisis, but they find that all agree that promoting healthy lifestyles must be an important part of the solution. Disagreement remain, but points of convergence emerge through discussion. For these points of convergence to emerge deliberation need to reveal the logic of competing proposals and give substance to proposal details. This allows deliberators to see how various proposals overlap and converge. Reaching common ground is an exercise in creative thinking, working through the logic of competing proposals and exploring points where they overlap. The deliberation present in the eight forums under study, however, did not foster this process. There were few instances of deliberators working through the logic of arguments to find common ground and conversations rarely reached a point where deliberators could see the common points of agreement in divergent positions. The failure of deliberators to work through disagreements made the realization of common ground highly unlikely.

Deliberation may still be valuable even if no agreement or common ground is reached. Participants may not agree on the substance of the arguments but develop a greater understanding and tolerance of opposing viewpoints (Gutmann and Thompson 2004; Price, Cappella, and Nir 2002). The idea is that by listening to others make arguments, one will better understand their logic. Rather than demonizing others and considering them illinformed and ignorant, after hearing their arguments one will recognize that at least there is some merit to their position, even if one disagrees with it. Deliberation here is seen as a palliative to the often shrill, confrontation style of political discourse found on talk radio or CNN. Mutual understanding is most likely to materialize through a discussion that explores disagreements in depth, where ideas are criticized and explored. For deliberators to understand an argument that they disagree with, they need to have a solid understanding of 
its logic and premises. If an argument is fully explicated, they may understand why others hold that position, realizing that if one starts from a certain premise or value then the proposal is a logical conclusion. A process where deliberators critique and question a proposal will help them reach such an understanding. On the other hand, comparing across proposals by itself will not generate much understanding; hearing a proposal is not what leads to understanding, but rather exploring its logic and premises is they key. Like with reaching common ground, there was not enough of this process during the forums under study to expect much mutual understanding to arise. Deliberators did not work through the logic of arguments in a way that would enhance their respect for opposing viewpoints.

A third potential outcome of deliberation is that participants will learn about politics or policy. They may not reach agreement, and they may not even reach a state of mutual understanding, but they will at least learn new information. This can be factual information or details about various arguments that people make concerning an issue, but either way the act of deliberating is a learning process. Learning can occur regardless of how participants address disagreements, but the type of learning will vary. A process where alternative proposals are presented may teach participants about policy options or highlight choices that need to be made, while a substantive critique of a proposal may lead to an understanding of the logic of an argument. How participants dealt with disagreement will not have a significant impact on learning specific facts about policy, although it could hinder the learning process when it comes to the nuances of policy proposals and the arguments underlying them. Participants may have learned quite a bit during these forums, as many facts and figures were bandied about, but the inability to fully work through disagreements hindered learning of the contours of arguments made; deliberators were unlikely to leave these forums with new knowledge of how others reason through policy issues.

In general, there is strong reason to believe that the manner in which deliberators dealt with disagreement undermined the likelihood of benefits from materializing. Future research should explore these hypotheses more explicitly, linking the types of discussions that deliberators have to theorized benefits. Scholars should also explore whether changes to the structure or organization of forums will influence how participants address disagreements. The one-time, off-the-top-of-the-head format of NIF forums may act to inhibit working through disagreements. If participants meet multiple times, they may feel less rushed and spend more time developing arguments and addressing those with whom they disagree. Further, if they had more time to think beforehand about their arguments they may be better able to formulate them. If moderators specifically prompted participants to respond to views they disagree with and followed up with probes to push participants to develop arguments, we may also see more robust working through. In these forums, moderators were generally not helpful in promoting working through, but they could be under different circumstances. Thus, the main tasks of future research is to explore factors 
that influence variation in how deliberators work through disagreements, as well as how this variation affects the realization of beneficial deliberative outcomes. 
Table 1: Overview of Forums

\begin{tabular}{|l|l|c|c|}
\hline Location & Issue & \# of participants* & Length \\
\hline Cedar Rapids, Iowa & Immigration & 16 & $2: 01$ \\
\hline El Paso, Texas & Energy & 21 & $1: 51$ \\
\hline Georgetown, Delaware & Immigration & 19 & $1: 27$ \\
\hline Hempstead, New York & Energy & 18 & $1: 54$ \\
\hline Kent, Ohio & Energy & 24 & $2: 00$ \\
\hline Mesa, Arizona & Immigration & 13 & $1: 44$ \\
\hline Pittsburgh, Pennsylvania & Health Care & 15 & $1: 52$ \\
\hline Rindge, New Hampshire & Immigration & 14 & $1: 52$ \\
\hline & Totals & $\mathbf{1 4 0}$ & $\mathbf{1 4 : 4 1}$ \\
\hline
\end{tabular}

*Excludes moderators 
Table 2: List of Disagreements

\begin{tabular}{|c|c|c|c|}
\hline Forum & Topic* & \# of Participants & $\#$ of comments** \\
\hline Cedar Rapids & $\begin{array}{l}\text { We should increase the number of legal } \\
\text { immigrants. }\end{array}$ & 3 & 7 \\
\hline Cedar Rapids & Immigrants on green cards don't pay taxes. & 3 & 12 \\
\hline Cedar Rapids & $\begin{array}{l}\text { A lot of opposition to immigration is based } \\
\text { on racial prejudice. }\end{array}$ & 3 & 6 \\
\hline Cedar Rapids & $\begin{array}{l}\text { Immigrants sending remittances home is a } \\
\text { drain on the economy. }\end{array}$ & 3 & 3 \\
\hline El Paso & $\begin{array}{l}\text { We need to rely on foreign countries for } \\
\text { energy. }\end{array}$ & 4 & 4 \\
\hline El Paso & $\begin{array}{l}\text { We need a "global government" to address } \\
\text { energy issues. }\end{array}$ & 2 & 4 \\
\hline El Paso & $\begin{array}{l}\text { People can initiate change at the grassroots } \\
\text { in regards to energy policy. }\end{array}$ & 3 & 5 \\
\hline El Paso & $\begin{array}{l}\text { We need a "national" approach to the } \\
\text { energy problem. }\end{array}$ & 3 & 6 \\
\hline Georgetown & $\begin{array}{l}\text { Immigrants should not be forced to learn } \\
\text { English because they will learn it on their } \\
\text { own. }\end{array}$ & 4 & 15 \\
\hline Georgetown & $\begin{array}{l}\text { All Americans should be able to speak } \\
\text { English. }\end{array}$ & 2 & 6 \\
\hline Georgetown & $\begin{array}{l}\text { We should open the borders and let } \\
\text { everyone in from oppressed countries. }\end{array}$ & 2 & 3 \\
\hline Georgetown & $\begin{array}{l}\text { Immigration is good because it provides } \\
\text { cheap labor that helps us compete globally. }\end{array}$ & 3 & 12 \\
\hline Hempstead & $\begin{array}{l}\text { Government should create incentives for } \\
\text { renewable energy. }\end{array}$ & 2 & 3 \\
\hline Hempstead & $\begin{array}{l}\text { Conservation is only a small part of the } \\
\text { solution to the energy problem. }\end{array}$ & 4 & 10 \\
\hline Hempstead & $\begin{array}{l}\text { We should get more energy from nuclear in } \\
\text { the short term. }\end{array}$ & 5 & 13 \\
\hline Kent & Wind power is a feasible option. & 4 & 5 \\
\hline Kent & $\begin{array}{l}\text { Government should promote innovation and } \\
\text { investment in energy. }\end{array}$ & 4 & 8 \\
\hline Kent & $\begin{array}{l}\text { Nuclear power is problematic because of } \\
\text { waste disposal. }\end{array}$ & 2 & 3 \\
\hline Kent & Plasma televisions use a lot of energy. & 2 & 2 \\
\hline Mesa & $\begin{array}{l}\text { Immigrants will come the US regardless of } \\
\text { economic conditions. }\end{array}$ & 2 & 2 \\
\hline Mesa & $\begin{array}{l}\text { Employers who hire illegal immigrants do } \\
\text { not pay taxes on them. }\end{array}$ & 2 & 2 \\
\hline Mesa & $\begin{array}{l}\text { Amnesty for illegal immigrants is a good } \\
\text { idea. }\end{array}$ & 4 & 6 \\
\hline
\end{tabular}




\begin{tabular}{|c|c|c|c|}
\hline Mesa & Day laborer centers are effective. & 7 & 9 \\
\hline Mesa & $\begin{array}{l}\text { Illegal immigrants should be able to pay-in- } \\
\text { state tuition at public universities. }\end{array}$ & 3 & 6 \\
\hline Pittsburgh & $\begin{array}{l}\text { The means exist to share health care } \\
\text { information while keeping it private. }\end{array}$ & 3 & 5 \\
\hline Pittsburgh & $\begin{array}{l}\text { People don't take responsibility for their } \\
\text { health because others pay for it. }\end{array}$ & 2 & 7 \\
\hline Pittsburgh & $\begin{array}{l}\text { Part of health care costs should be paid } \\
\text { directly by patients. }\end{array}$ & 4 & 13 \\
\hline Pittsburgh & $\begin{array}{l}\text { We should have universal healthcare } \\
\text { coverage. }\end{array}$ & 4 & 20 \\
\hline Pittsburgh & Government should not run healthcare. & 2 & 11 \\
\hline Pittsburgh & Seniors don't complain about Medicare. & 2 & 6 \\
\hline Rindge & $\begin{array}{l}\text { Immigrants need to learn English to } \\
\text { succeed. }\end{array}$ & 4 & 15 \\
\hline Rindge & Bilingual education programs are effective. & 2 & 4 \\
\hline Rindge & $\begin{array}{l}\text { Amnesty for illegal immigrants would be } \\
\text { beneficial. }\end{array}$ & 9 & 11 \\
\hline Rindge & $\begin{array}{l}\text { Immigrants on H1B visas get paid less than } \\
\text { native-born workers. }\end{array}$ & 2 & 5 \\
\hline Rindge & $\begin{array}{l}\text { We don't need to recruit nurses from } \\
\text { overseas. }\end{array}$ & 3 & 6 \\
\hline Rindge & $\begin{array}{l}\text { We should not focus solely on economics } \\
\text { when dealing with the immigration } \\
\text { question. }\end{array}$ & 5 & 7 \\
\hline Rindge & $\begin{array}{l}\text { We need to set limits on immigration, and } \\
\text { then admit people based first on family, } \\
\text { then economics, then political factors. }\end{array}$ & 2 & 6 \\
\hline
\end{tabular}

* The topic is defined by the initial comment that prompted another deliberator to disagree.

**Not all comments were directly related to the disagreement - the numbers in this column are a count of comments from the initial statement to the end of the exchange. Also, short interjections such as "right" or "I see" are not counted as comments. 


\section{References}

Barber, Benjamin. 1984. Strong Democracy: Participatory Politics for a New Age. Berkeley: California.

Bickford, Susan. 1996. The Dissonance of Democracy: Listening, Conflict, and Citizenship. Ithaca: Cornell University Press.

Bohman, James. 1996. Public Deliberation: Pluralism, Complexity, and Democracy. Cambridge, MA: MIT Press.

Button, Mark, and Kevin Mattson. 1999. "Deliberative Democracy in Practice: Challenges and Prospects for Civic Deliberation." Polity 31 (4):609-37.

Cohen, Joshua. 1998. "Democracy and Liberty." In Elster, Jon, ed. Deliberative Democracy. Cambridge: Cambridge University Press.

Delli Carpini, Michael X., Fae Lomax Cook, and Lawrence R. Jacobs. 2004. "Public Deliberation, Discursive Participation, and Citizen Engagement: A REview of the Empirical Literature." Annual Review of Political Science 7:314-44.

Eliasoph, Nina. 1998. Avoiding Politics: How Americans produce apathy in everyday life. Cambridge: Cambridge.

Fishkin, James S. 2009. When the People Speak. New York: Oxford University Press.

Gastil, John. 2008. Political Communication and Deliberation. Los Angeles: Sage.

Goidel, Robert K., Craig Malcolm Freeman, Steven Procopio, and Charles F. Zewe. 2008. "Who Participates in the Public Square and Does it Matter?" Public Opinion Quarterly 72 (4):792-803.

Gutmann, Amy, and Dennis Thompson. 1996. Democracy and Disagreement. Cambridge, MA: Belknap Press.

Gutmann, Amy, and Dennis Thompson. 2004. Why Deliberative Democracy? Princeton: Princeton University Press.

Hibbing, John R., and Elizabeth Theiss-Morse. 2002. Stealth Democracy. New York: Cambridge University Press.

Karpowitz, Christopher F. and Jane Mansbridge. 2005. "The Importance of Dynamic Updating in Public Deliberation." In Gastil, John, and Peter Levine, eds. 2005. The Deliberative Democracy Handbook. San Francisco: Jossey-Bass. 
Mansbridge, Jane J. 1980. Beyond Adversary Democracy. New York: Basic Books.

Mathews, David. 1999. Politics for People: Finding a Responsible Public Voice. 2nd ed. Urbana, Ill: Illinois.

Price, Vincent, Joseph N. Cappella, and Lilach Nir. 2002. "Does Disagreement Lead to More Deliberative Opinion?" Political Communication 19 (1):95-112.

Ryfe, David M. 2005. "Does Deliberative Democracy Work?" Annual Review of Political Science 8:49-71.

Sanders, Lynn M. 1997. "Against Deliberation." Political Theory 25 (3):347-76.

Stromer-Galley, Jennifer. 2007. "Measuring Deliberation's Content: A Coding Scheme." Journal of Deliberation 3 (1):1-35. 